\title{
Rancang Bangun Simulasi Supervisory Control And Data Acquisition (SCADA) Main Distribution Panel (MDP) Berbasis Programmable Logic Controller (PLC)
}

\author{
Suhanto \\ Program Studi D3 Teknik Listrik Bandar Udara \\ Akademi Teknik dan Keselamatan Penerbangan Surabaya \\ Jemur Andayani I/73 Wonocolo Surabaya 60236 \\ Telp. (031)8410871, Fax. (031) 8490005 \\ Email : nadiafather@gmail.com
}

\begin{abstract}
SCADA (Supervisory Control And Data Acquisition) adalah sistem kendali listrik berbasis komputer yang dipakai untuk pengontrolan suatu sistem. Sistem disini dapat berupa sistem distribusi listrik, pengoprasian mesin pabrik, untuk pendistribusian air, sistem bandara dan lain sebagainya. Fungsi utama sistem SCADA adalah untuk mendukung operasi telemetri distribusi, alarm, rekaman kejadian, dan remote kontrol untuk peralatan lapangan. Sistem SCADA dalam penelitian ini dimanfaatkan untuk kontrol dan monitoring panel Main Distribution Panel (MDP). Dalam percobaan telah dilakukan pengujian untuk mengetahui apakah alat yang di buat sesuai dengan rancangan. Terdapat berbagai pengujian untuk beberapa komponen yang di pergunakan. Seperti PLC dapat berjalan dan mengaktifkan kontak point dengan inputan sumber power supply 24 VDc. Untuk arduino dapat bekerja setelah mendapat input sumber 5 Vdc dari komputer. Untuk sensor arus dapat membaca arus 0.01A, 0.17A, 0.33A dan untuk pembacaan sensor tegangan mendapat nominal 189 Vac. Untuk relay, buzzer dan beban dalam percobaan dapat bekerja secara normal. Kelebihan dari rancangan simulasi sistem SCADA ini adalah dapat mempermudah kerja teknisi dalam hal monitoring dan kontrol beban MDP. Sehingga efisiensi kerja dan waktu dalam penanganan sistem kontrol dan monitoring dapat diatasi dengan baik.
\end{abstract}

Keywords : Supervisory Control And Data Acquisition, Progammable Logic Controller, Main Distribution Panel

\section{PENDAHULUAN}

\section{Latar Belakang}

Pada era globalisasi saat ini listrik merupakan sumber energi utama di bumi. Kehadiran energi listrik adalah suatu hal yang paling signifikan dan paling penting keberadaannya. Suatu Sistem Supervisory Control And Data Acquisition (SCADA) merupakan aplikasi yang mendapatkan data-data suatu sistem di lapangan dengan tujuan untuk pengontrolan dan pemantauan suatu sistem.

$S C A D A$ berfungsi sebagai sebuah sistem monitoring dan kontrol secara terpusat terhadap banyak kegiatan misalkan kegiatan industri, sistem pembangkit, jaringan distribusi listrik dan lain sebagainya.

Mengingat saat ini energi listrik adalah energi yang sanagat penting bagi manusia. Di perlukan sebuah simulasi sistem kontrol maupun monitoring yang dapat menunjang kelancaran distribusi listrik pada panel distribusi MDP 3 di Akademi Teknik dan Keselamatan Penerbangan Surabaya.

\section{Rumusan Masalah}

1. Bagaimana mengontrol dan memonitoring pada MDP menggunakan simulasi sistem Supervisory Control And Data Acquisition (SCADA).

2. Bagaimana mengontrol dan memonitoring panel MDP secara terpusat menggunakan komputer. 


\section{TINJAUAN PUSTAKA}

\section{Supervisory Control And Data Acquisition (SCADA)}

SCADA (Supervisory Control And Data Acquisition) adalah sistem kendali listrik berbasis komputer yang dipakai untuk pengontrolan suatu sistem.

Beberapa contoh lain dari sistem SCADA ini banyak dijumpai di lapangan produksi minyak dan gas (Upstream),Jaringan Listrik Tegangan Tinggi dan Tegangan Menengah (Power Transmission and Distribution) dan beberapa aplikasi yang dipakai untuk memonitor dan mengontrol areal produksi yang cukup luas.

Yang dimaksud dengan Supervisory Control atau Master Terminal Unit (MTU) adalah kendali yang dilakukan di atas kendali lokal atau Remote Terminal Unit (RTU). Pada umumnya jarak antara RTU dengan MTU cukup jauh sehingga diperlukan media komunikasi antara keduanya. Pengaturan sistem tenaga listrik yang komplek, sangat bergantung kepada SCADA. Tanpa adanya sistem SCADA, sistem tenaga listrik dapat diibaratkan seperti seorang pilot membawa kendaraan tanpa adanya alat instrumen dihadapannya. Pengaturan sistem tenaga listrik dapat dilakukan secara manual ataupun otomatis. Pada pengaturan secara manual, operator mengatur pembebanan pembangkit dengan melihat status peralalatan listrik yang mungkin dioperasikan misalnya Circuit Breaker (CB), beban suatu pembangkit, beban trafo, beban suatu transmisi atau kabel dan mengubah pembebanan sesuai dengan frekuensi sitem tenaga listrik. Pengaturan secara otomatis dilakukan dengan aplikasi Automatic Generating Control (AGC) atau Load Frequency Control (LFC) yang mengatur pembebanan pembangkit berdasar setting yang dihitung terhadap simpangan frekuensi.

\section{Main Distribution Panel (MDP)}

MDP adalah panel distribusi utama yang mempunyai fungsi utama menerima suplai listrik baik dari PLN maupun dari sumber listrik lainnya seperti genset kemudian membagi-bagikannya ke seluruh beban. MDP dicatu dari 2 sumber listrik dengan genset sebagai cadangan sehingga bila suplai listrik dari PLN mati, suplai listrik untuk beban essential tetap terpenuhi. MDP berisi komponen-komponen listrik dan non listrik, komponen-komponen yang terpenting adalah pertama busbar sebagai konduktor yang menghantar listrik dan harus tahan terhadap arus hubung singkat. Kedua switchgear,yaitu CB sebagai pengaman arus lebih dan arus hubung singkat, kontaktor, LBS (load break switch) dan fuse. Setiap saluran harus mempunyai pengaman arus lebih dan hubung singkat. Ketiga terminal kabel yaitu sepatu kabel, terminal block yang digunakan untuk sambungan kabel. Yang keempat adalah peralatan ukur dengan tujuan utama untuk keamanan peralatan, pengawasan dan mengetahui kapasitas produksi. Yang kelima adalah pentanahan yaitu saluran pengaman yang akan mengalirkan arus lebih ke dalam tanah bila terjadi hubung singkat.

\section{Programmable Logic Controller (PLC)}

Sebuah programmable logic controller, PLC, atau pengontrol yang dapat diprogram adalah komputer digital yang digunakan untuk otomatisasi proses biasanya industri elektromekanis, seperti kontrol mesin di lini pabrik perakitan, wahana hiburan, atau lampu. PLC digunakan di banyak mesin, di banyak industri. PLC dirancang untuk beberapa pengaturan input digital dan analog dan output, suhu berkisar diperpanjang, kekebalan terhadap gangguan listrik, dan ketahanan terhadap getaran dan dampak. Program untuk mengendalikan operasi komputer biasanya disimpan dalam baterai yang didukung-up atau memori non-volatile. Sebuah PLC adalah contoh dari "keras" sistem real-time sejak 
hasil output yang dihasilkan harus dalam menanggapi masukan dalam kondisi waktu yang terbatas, jika tidak akan menghasilkan operasi.

Sebelum PLC, kontrol, sequencing, dan keselamatan interlock logika untuk pembuatan mobil terutama terdiri dari relay, cam timer, sequencer gendang, dan berdedikasi pengendali loop tertutup. Sejak Ulasan ini bisa nomor di ratusan atau bahkan ribuan, proses untuk memperbarui fasilitas untuk tahunan model perubahan-atas sangat memakan waktu dan mahal, karena listrik diperlukan untuk individual rewire relay untuk mengubah Ulasan karakteristik operasional mereka.

Komputer digital, menjadi tujuan umum perangkat diprogram, segera diterapkan untuk mengontrol proses industri. Awal komputer diperlukan programmer spesialis, dan operasi pengendalian lingkungan yang ketat untuk suhu, kebersihan, dan kualitas daya. Menggunakan tujuan umum pengendalian proses komputer yang dibutuhkan untuk melindungi komputer dari kondisi lantai pabrik. Komputer kontrol industri akan memiliki beberapa atribut itu akan mentolerir lingkungan toko-lantai, akan mendukung diskrit (bit-bentuk) input dan output dengan cara mudah extensible, tidak akan memerlukan tahun pelatihan untuk menggunakan, dan itu akan mengizinkan operasinya dipantau. Waktu respon dari setiap sistem komputer harus cukup cepat untuk menjadi berguna untuk kontrol; kecepatan yang dibutuhkan bervariasi Menurut sifat dari proses. Karena banyak proses industri memiliki rentang waktu Mudah ditangani oleh waktu respon milidetik, modern (cepat, kecil, terpercaya) elektronik sangat memfasilitasi membangun pengendali terpercaya, terutama karena kinerja dapat diperdagangkan untuk keandalan.

Dalam hal ini penulis menggunakan PLC zelio pabrikan Schneider. Karena disesuaikan dengan kebutuhan dalam pembuatan alat dan juga untuk memudahkan penulis dalam mengerjakan alat. Selain itu PLC zelio ini juga mudah di operasikan oleh semua orang yang masih awam terhadap PLC.

\section{KONSEP RANCANGAN}

Dalam penelitian ini peneliti merancang sistem HMI seperti SCADA untuk memonitoring dan kontrol pada panel MDP secara terpusat dengan membuat simulasi rancangan sistem pengontrolan dan pemantauan beban distribusi listrik secara terpusat yang membantu teknisi atau petugas terkait dalam melakukan pengecekan distribusi listrik di panel MDP, pemantauan distribusi listrik di panel MDP, dan pengecekan distribusi panel MDP jika terjadi kerusakan dapat ditindaklanjuti secara cepat. Adapun blok diagram rancangan sebagai berikut :

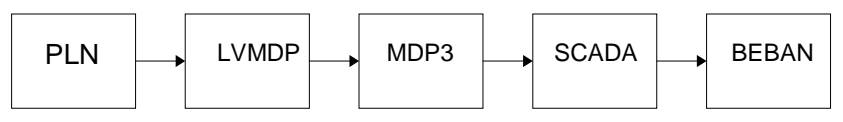

Gambar 1. Blok Diagram Rancangan

Dari blok diagram di atas dapat di lihat bahwa tampilan SCADA menjadi tampilan utama sistem kontrol dan monitoring. Selai itu juga menjadi tampilan dari nominal sensor suhu dan tegangan pada beban. Sistem SCADA akan ditampilkan oleh Personal Komputer yang menjadi alat kontrol dari panel RTU, terdapat berbagai komponen seperti PLC, mikro, relai, sensor, mcb dan lain sebagainya yang menunjang sistem monitoring dan kontrol. Relai dijadikan sebagai pengganti kontaktor untuk sistem kontrol. MCB dijadikan alat simulasi dari sistem pegaman MCCB yang terdapat pada panel MDP. Mikro dijadikan sebagai alat pengolah data dari sensor arus dan tegangan yang dibaca oleh sensor yang telah dipasang di beban yang di kontrol dan di monitoring. 
Jadi dari personal komputer operator dapat mengontrol semua beban pada MDP, termasuk mengatur relay untuk menyala atau mati melalui tampilan diagram wiring pada instalasi jaringan dari panel MDP. Jadi jika ingin memutus atau menghubungkan suplay daya ke beban dapat dilakukan melalui gambar layar berupa swicth. Kemudian kontak penghubung NO (Normally Open) atau NC (Normally Close) relay dihubungkan dengan sumber load atau beban. Pada blok diagram di atas juga terdapat sensor arus yang berfungsi untuk memonitor arus dan tegangan masuk pada beban yang kemudian datanya akan diteruskan ke personal komputer. Dari personal komputer data akan diolah dan ditampilkan pada HMI (Human Machine Interface) dalam hal ini adalah tampilan SCADA. Untuk pemberitahuan ketika terjadi trouble sistem akan memberikan advice atau pemberitahuan barupa gambar perubahan warna pada diagram wiring yang ada pada personal komputer pada operator.

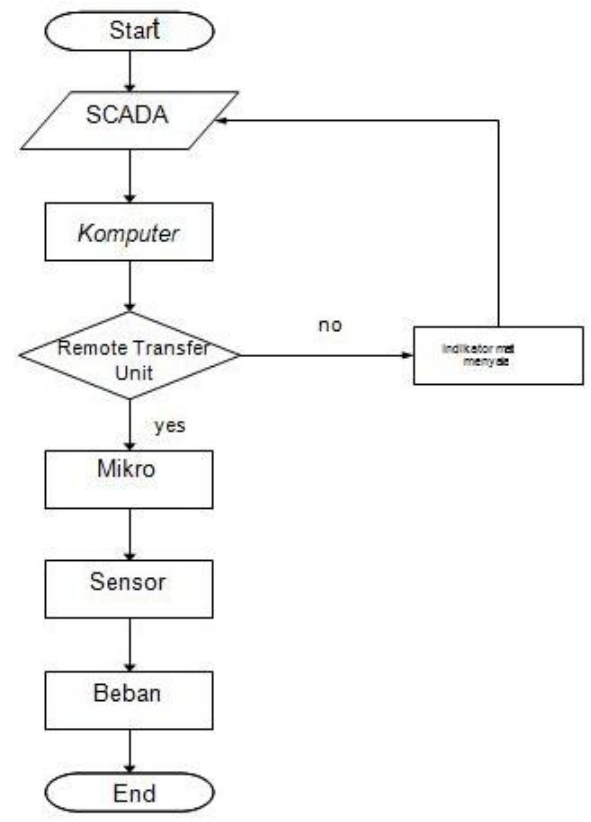

Gambar 2. Flow Chart System

Tampilan SCADA akan menampilkan load atau beban telah mendapat suplai listrik dengan perubahan warna pada gambar wiring yang semisal awalnya line kabel pada wiring berwarna merah yang maksutnya beban belum mendapat suplai akan berubah warna menjadi hijau jika tersuplai oleh listrik. Dan gambar simbol dari kontak relai akan menjadi normaly close atau tertutup. Kemudian semua sensor akan mebaca arus dan tegangan dari beban yang telah mendapat supali listrik yang data nominalnya akan diolah oleh mikrokontroller dalam hal ini yang dipakai adalah arduino yang akan mengirimkan data ke Remote Transfer Unit (RTU) untuk dikirim ke server.

Dalam hal ini server yang dimaksud adalah Personal Komputer (PC) yang dijadikan sebagai main server untuk menyimpan data dan sebagai sarana dari pemrograman dan penampilan dari simulasi sistem $S C A D A$ yang penulis buat. Setelah itu tampilan $S C A D A$ akan meampilkan gambar wiring yang menandakan bahwa beban tesuplai oleh listrik. Selain itu tampilan simulasi sistem SCADA juga akan menampilkan besar nominal dari pembacaan arus dan tegangan yang dilakukan oleh sensor.

Kemudian jika terjadi gangguan, listrik padam atau PLN off, maka tampilan simulasi sistem $S C A D A$ akan berubah. Yang semula gambar wiring dari suplai beban berwarna hijau yang menandakan adanya suplai listrik berubah menjadi warna merah yang menandakan suplai listrik tidak ada atau off. Dan gambar simbol dari kontaktor akan terbuka atau open. Selain itu tampilan dari pembacaan arus dari beban akan mati. Jadi operator dapat menyalakan atau mematikan suplay daya pada beban dari panel MDP dan dapat memonitoring langsung jalur instalasi jaringan panel MDP 


\section{Sensor Arus}

ACS712 merupakan IC yang berfungsi sebagai sensor arus dan menggantikan trafo arus yang relatif besar dalam bentuk fisiknya. Sensor ACS712 ini adalah sensor yang langsung bisa di sambungkan ke arduino tanpa harus menggunakan rangkaian penguat sebagai penguat daya sensor yang di butuhkan untuk memasukkan data arus pada arduino. Sensor ACS712 ini langsung bisa mendapat inputan power dari arduino dengan input vs sumber 5v dan ground dari arduino. kemudian untuk memasukkan data sensor arus pada arduino sensor ACS 712 menjadi masukkan pada port inputan arduino pada port 0 . Bisa di lihat pada gambar sebagai berikut :

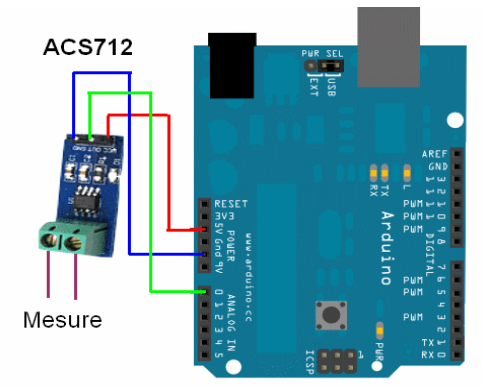

Gambar 3. Skema sensor arus ACS 712

Sensor arus ACS712 dimana memiliki 8 pin, dalam hal ini ACS712 bertindak sebagai penyensor dan dalam rangkaian ini data yang didapat berupa data analog dan kemudian diubah menjadi data digital agar dapat diolah oleh arduino yang selanjutnya data digital tersebut dapat disajikan menjadi sebuah data yang termonitor.

\section{Sensor Tegangan}

Pada rangkaian sensor tegangan untuk memonitoring tegangan yang masuk pada beban menggunakan sensor tegangan ZMPT101B.

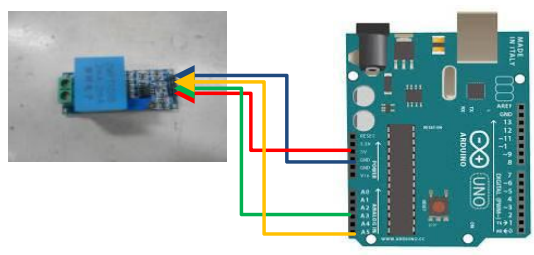

Gambar 4. Skema sensor Tegangan ZMPT

Pada perencanaan monitoring tegangan yang di rencanakan, penulis menggunakan sensor tegangan ZMPT untuk membuat sistem monitoring yang mudah dan keakurasian yang tepat . Sensor ini dapat dipergunakan untuk memonitor tegangan AC ( Alternating Current ).

Sensor tegangan ZMPT ini akan di sambungkan pada modul arduino yang diguakan sebagai pengirim dan penerimaan data pada proses sensor tegangan yang nantinya dapat di tampilkan pada personal komputer yang di jadikan sebagai alat kontrol dan monitoring pada Simulasi sistem SCADA yang penulis buat. Sambungan pada sensor tegangan ini pada port tegangan 5v kemudian port 2 yang ada di tengah masuk ke pin analog A3 dan 5 selanjutnya port aport yang paling bawah adalah untuk ground. Sensor ini dapat dipergunakan untuk memonitor tegangan AC ( Alternating Current). 


\section{Arduino}

Dalam rancangan ini mikrokontroler digunakan sebagai media untuk sensor. Maksudnya adalah bila beban menyala mendapatkan suplai listrik, maka sensor akan membaca arus dan tegagan yang masuk ke beban sehingga mikro dapat menampilkan nominal arus dan tegangan yang mengalir ke beban pada layar komputer. Apabila tidak ada suplai yang masuk ke beban, maka pembacaan sensor tidak dapat di lakukan dan tomatis pembacaan arus di layar akan mati. Serta arduino tidak dapat menampilkan nominal arus yang mensuplai beban.

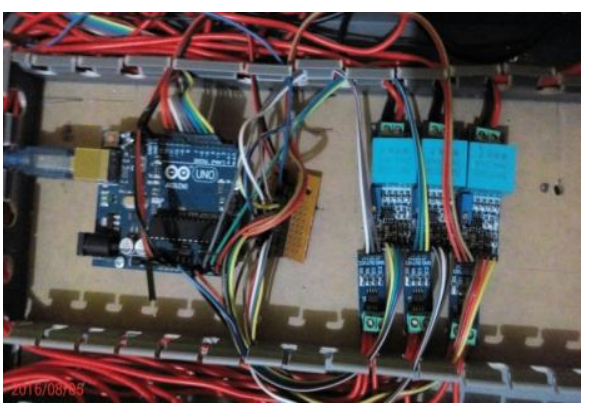

Gambar 5. Gambar rangkaian mikrokontroler arduino uno

Pada penyambungan aduino terhadap PLC yaitu dengan menghubungkan antara port digital arduino dengan port analog pada PLC. Keluaran pada port analog Arduino sebesar 24 Vdc yang dapat mengenergize port pada PLC untuk aktif. Pada Port digital arduino yaitu mulai port 2, 3, 4, 5, 6, 7, 8, 9. Masing-masing port terhubung ke PLC pada port IB, IC, ID, IF, IG, I1 dan I2. Kemudian untuk sambungan yang lain arduino di sambungkan pada sensor arus maupun sensor tegagan. Pada port analog dari arduino disambungkan ke sensor arus melalui port vec yaitu sumber, port GND yaitu ground, dan port Out pada sensor arus. Dari port arduino A0 disambungkan ke port vec pada sensor arus. Untuk port ground pada arduino disambungkan juga ke port ground sensor arus.

Selanjutnya untuk port A1 di masukkan pada port out sebagai pembacaan hasil dari sensor arus. Pada rangkaian sensor tegangan sama dengan sensor arus. Dari port analog A2 dimasukkan pada port vcc pada sensor tegangan. Kemudian untuk ground sama di masukkan pada ground dari sensor tegangan. Selanjutnya untuk port out pada sensor tegangan di masukkan pada port A3 pada arduino untuk pembacaan sensor yang telah di baca oleh sensor tegangan.

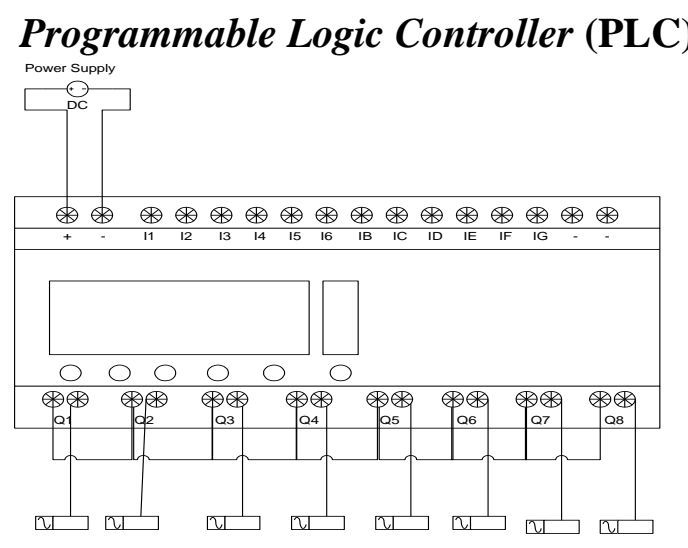

Gambar 6. Gambar wiring PLC 
Pada hardware PLC penulis menggunakan PLC Zelio. PLC ini memiliki 12 port input dan 8 port output. Sesuai dengan beban yang akan di kontrol dan di monitoring oleh penulis. PLC ini juga memiliki LCD yang dapat digunakan untuk menampilkan monitoring arus dan tegangan dari hasil data pengukuran yang di lakukan oleh sensor arus maupun tegangan. Pada wiring diatas pada input power untuk PLC dapat menggunakan power supply dengan tegangan $24 \mathrm{Vdc}$.

Kemudian untuk port inputan yang lain mendapat sambungan dari outputan perintah dari arduino. Output perintah dari arduino yang dimaksud yaitu sambungan antara arduino dengan PLC mengguakan port digital dari arduio ke port analog dari inputan PLC. Hubungan kedua alat ini yaitu arduino sebagai suplai inputan sumber bagi kontak point PLC sebesar 24 Vdc yang akan mengenergize kontak dari PLC untuk memutus atau menyambung. Port yang di pakai dari arduino yaitu port digital 2-IB, 3-IC, 4-ID, 5-IE, 6-IF, 7-IG, 8-I1, 9-I2. Kemudian untuk output dari PLC di sambungkan ke soket relai pada soket normaly close. Berikut ini adalah ladder dari PLC zelio :

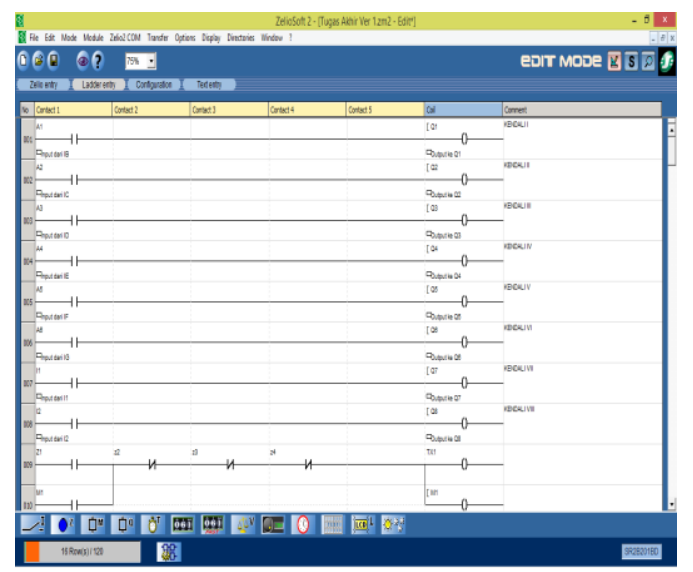

Gambar 7. Gambar Ladder Software

Gambar diatas merupakan rangkaian penyususnan ladder untuk sistem kontrol pada pael Simulasi sistem SCADA oleh PLC. Pada gambar di atas ada 8 port output masing-masing memiliki satu kontrol untuk di hubungkan ke relai pada panel sebagai alat kontrol untuk perintah on atau off dari jarak jauh. Dalam ladder tersebut ada beberapa kode dari kontak point pada PLC. Dari kode A1 adalah kode dari inputan perintah PLC yaitu untuk IB yang akan memberi perintah ke kontak Q1 untuk untuk memutus atau menyambungkan kontak poin. Untuk A2 inputan dari IC memberi perintah kontak Q2 untuk memutus atau manyambungkan kontak poin. A3 mewakili dari ID memberi perintah Q3 untuk memutus atau menyambungkan kontak poin. Begitu juga selanjutnya dengan prinsip yang sama A4 Untuk kontak Q4, A5 untuk mengontak Q5, A6 untuk mengontak Q6, I1 untuk megontak Q7 dan I2 untuk mengontak Q8.

\section{PENGUJIAN DAN ANALISA}

Pada pengujian ini dijelaskan lebih rinci mengenai proses kerja alat dari komponen-komponen yang digunakan agar alat ini berjalan sesuai dengan fungsinya. Dan juga akan dibahas tentang perangkat keras yang digunakan dalam perancangan alat. Untuk lebih jelas dari perangkat keras tersebut, maka penulis akan membahas secara terperinci.

\section{Perangkat Keras}

\section{Pengujian Pada Power Supply}


Alat yang digunakan 1) Power supply 24 dc. 2) Avo meter

Tata cara untuk pengujian Power Supply $24 \mathrm{Vdc}$ :

1. Siapkan Power Supply $24 \mathrm{Vdc}$ yang akan diujikan

2. Hubungkan output power supply $24 \mathrm{Vdc}$ ke coil relay.

3. Lalu lihat hasil pengukuran yang di tunjukkan oleh Power Supply pada avo meter seperti gambar di bawah ini.

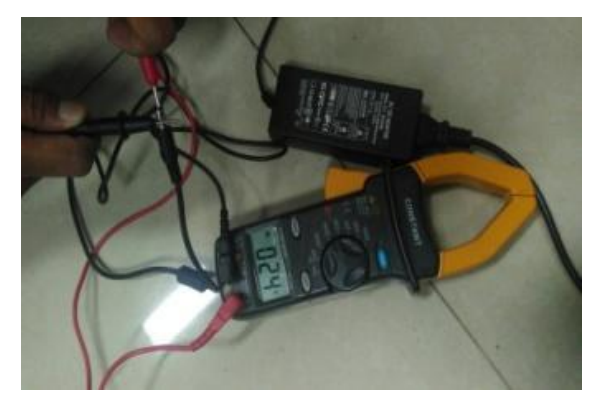

Gambar 8. Pengujian Power Supply

Tegangan yang di keluarkan dari power supply diatas adalah $24 \mathrm{Vdc}$ yang menujukkan bahwa power supply tersebut bekerja sesuai yag di harapkan. Kemudian untuk tegangan keluaran tidak terdapat kekurangan bisa dilihat pada gambar sesuai dengan spesifikasi dari power supply dengan outpu tegangan 24 Vdc agar dapat mensuplai sumber pada PLC.

\section{Pengujian pada PLC}

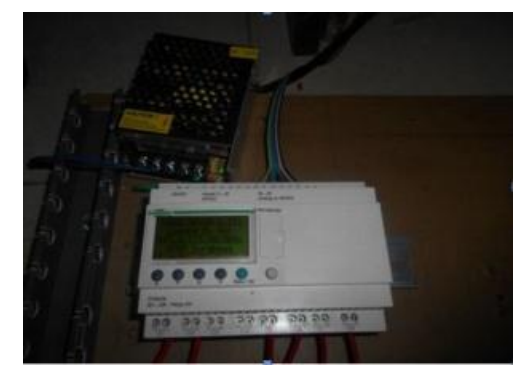

Gambar 9. PLC Zelio Schneider

PLC ini membutuhkan inputan dari power supply dengan tegangan $24 \mathrm{Vdc}$. Untuk mengujinya sambungkan output dari power supply $24 \mathrm{Vdc}$ ke port + dan - pada PLC. Kemudian tunggu berapa saat, ketika layar LCD PLC menyala dan muncul tampilan dari PLC maka PLC bisa digunakan.

\section{Pengujian Arduino}

Untuk pengujian rangkaian sensor arus dan tegangan menggunakan Arduino yang berfungsi sebagai sebagai pembacaan nominal dari arus maupun tegangan yang berasal dari sumber menuju ke beban. 


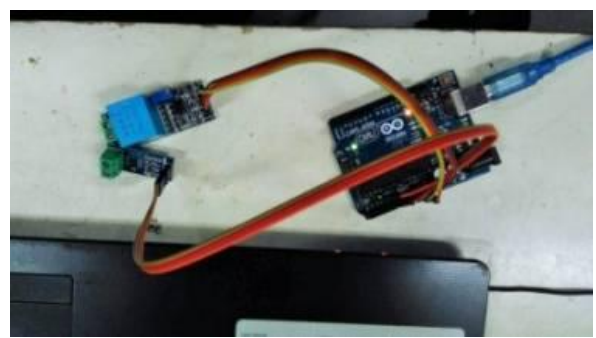

Gambar 10. Arduino

Cukup dengan kabel serial Usb yang digunakan untuk mengkoneksikan arduino dengan personal komputer. Dari hasil uji coba yang telah penulis lakukan arduino menyala dengan baik. Hal itu bisa di buktikan dengan lampu indikator dari arduino yang menyala.

\section{Pengujian pada Relay}

Alat yang digunakan 1) Relay 24 VDC, 2) Power supply 24 VDC

Tata cara untuk pengujian relay $24 \mathrm{VDC}$ :

1. Siapkan relay 24 VDC yang akan diujikan

2. Hubungkan output power supply 24 VDC ke coil relay.

3. Apabila relay tersebut energize berarti relay tersebut telah mendapat tegangan sesuai dengan yang diinginkan.

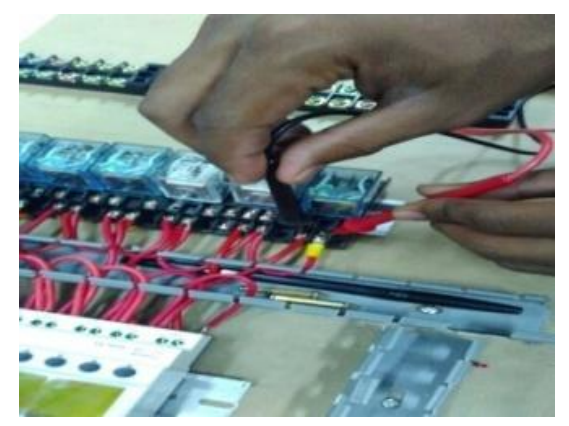

Gambar 11. Pengujian pada coil relay

Dari hasil pengujian didapatkan data untuk semua relay energize pada saat mendapat input 24 VDC. Setelah dilakukan beberapa rangkaian dari pengujian relay 24 volt DC, penulis mendapat data pengujian bahwa relay dapat bekerja dengan baik.

\section{Pengujian pada Sensor ACS}

Alat yang digunakan 1) Sebuah sensor arus ACS, 2) Beban beberapa lampu, 3) Tang Ampere.

Tata cara pengujian sensor arus:

1. Siapkan sensor arus yang akan diuji

2. Pasang sensor arus pada beban penerangan

3. Samakan antara angka yang dihasilkan sensor arus dengan angka yang dihasilkan tang ampere. 


\begin{tabular}{|c|c|c|}
\hline Nama beban & Hasil Pengukuran & Hasil Pembacaan Sensor Arus \\
\hline Lampu pijar $15 \mathrm{w}$ & $0,01 \mathrm{~A}$ & $0.01 \mathrm{~A}$ \\
\hline Lampu pijar $40 \mathrm{w}$ & $0.18 \mathrm{~A}$ & $0.17 \mathrm{~A}$ \\
\hline Lampu pijar $75 \mathrm{w}$ & $0.35 \mathrm{~A}$ & $0.33 \mathrm{~A}$ \\
\hline
\end{tabular}

Table 1. Tabel hasil percobaan

\section{Pengujian Sensor Tegangan}

Untuk pengujian ini digunakan sensor tegangan ZMPT101B, beban lampu, alat ukur (Tang Ampere atau AVO meter)

Tata cara pengujian sensor arus :

1. Siapkan sensor tegangan yang akan diuji

2. Pasang sensor tegangan pada beban penerangan

3. Samakan antara angka yang dihasilkan sensor dengan angka yang dihasilkan alat ukur

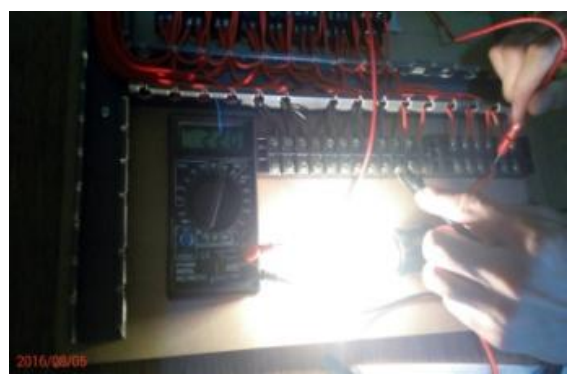

Gambar 12. Hasil pengukuran sensor tegangan

Sensor yang digunakan dalam kondisi normal dan dapat membaca tegangan yang mengalir. Data yang di-sensing oleh sensor ini, nantinya akan diolah oleh mikrokontroler hingga dapat ditampilkan melalui komputer. Dari percobaan tersebut alat ukur atau avometer menunjukkan angka 220 Vac dengan sampel tegangan pada saluran output dari relay yang menuju ke beban.

\section{Perangkat Lunak Wonderware}

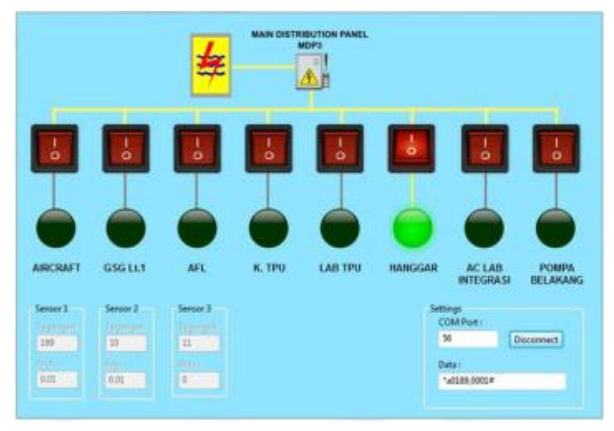

Gambar 13. Interface SCADA

Pada gambar tampilan Interface diatas penulis menyalakan salah satu beban yaitu simulasi beban Hanggar. Kemudian pada sensor muncul angka pembacaan sensor arus dan tegangan. Pada gambar ber bentuk lingkara, ada perbedaan warna dari setiap gambar yang ada pada interface. Ketika gambar saklar di tombol on maka gambar lingkaran di bawahnya yang menandakan beban aka berubah 
warna menjadi warna hijau yang warna awalanya hijau gelap. Dan garis yang awalnya berwarna gelap menjadi warna kuning ketika saklar di aktifkan. Perubahan itu menandakan bahwa saluran tersebut sedang aktif atau menyala. Namun ketika tombol saklar di matikan maka gambar lingkaran yang jika aktif menyala warna hijau muda kembali seperti semula menjadi warna hijau gelap.

Perubahan yang menandakan bahwa saluran tersebut off atau tidak menyala. Pada kolom di bawah tulisan "Sensor 1" muncul nominal pembacaan sensor arus maupun tegangan denga pembacaan sensor tegangan sebesar 189 Vac dan pembacaan arus yaitu sebesar 0,01 A.

\section{KESIMPULAN}

1. Pada pembacaan arus menggunakan sensor arus ACS712 pada 3 beban yang menjadi sampel di dapatkan hasil pengukuran beban 0.17 Ampere dengan beban lampu pijar 45 watt, 0.42 Ampere untuk beban solder, dan 0.34 Amper untuk beban kipas 120 watt.

2. Pada pembacaan tegangan menggunkan sensor tegangan ZMPT pada 3 beban yang menjadi sampel di dapatkan hasil pengukuran tegangan pada beban 189 Vac untuk beban lampu pijar 45 watt, 192 Vac untuk beban solder dan 190 untuk beban kipas 120 watt.

3. Untuk kontrol beban pada saat menyalakan dan mematikan beban membutuhkan waktu 5 detik agar tidak terjadi error pada pembacaan sensor.

\section{DAFTAR PUSTAKA}

[1] Setiawan Iwan, Programmable Logic Controller (PLC) dan Teknik Perancangan Sistem Kontrol, 2006, Penerbit Andi

[2] Artanto, Dian, Buku 60 Aplikasi PLC-MIKRO, 2012

[3] --------, Intructions and Programming. XBC_XGB_XGK, 2009

[4] Kadir, A, Panduan Praktis Mempelajari Aplikasi Mikrokontroler dan Pemogramannya Menggunakan Arduino, 2012.. Penerbit Andi, Yogyakarta,

[5] Suhana dan Shoji, S. Teknik Telekomunikasi, 2002. Pradnya Paramita, Jakarta,

[6] Blocher, R. Dasar Elektronika, 2004 Penerbit Andi, Yogyakarta.

[7] Maysidi, Wawan, Canggih Berteknologi, 2011, Graha Ilmu: Yogyakarta 